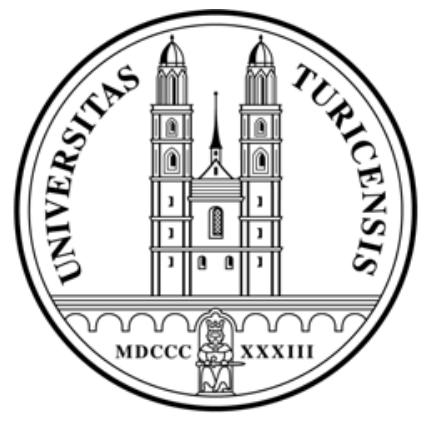

Institute for Empirical Research in Economics

University of Zurich

Working Paper Series

ISSN 1424-0459

Working Paper No. 291

Testing the Predictions of Decision Theories in a Natural Experiment When Half a Million Is at Stake

Pavlo Blavatskyy and Ganna Pogrebna

June 2006 


\title{
Testing the Predictions of Decision Theories in a Natural Experiment When Half a Million Is at Stake*
}

\author{
Pavlo Blavatskyy ${ }^{\dagger}$ and Ganna Pogrebna ${ }^{\star}$
}

June 2006

\begin{abstract}
In the television show Affari Tuoi an individual faces a sequence of binary choices between a risky lottery with equiprobable prizes of up to half a million euros and a monetary amount for certain. The decisions of 114 show participants are used to test the predictions of ten decision theories: risk neutrality, expected utility theory, fanning-out hypothesis (weighted utility theory, transitive skew-symmetric bilinear utility theory), (cumulative) prospect theory, regret theory, rank-dependent expected utility theory, Yaari's dual model, prospective reference theory and disappointment aversion theory. Assumptions of risk neutrality and loss aversion are clearly violated, respectively, by $55 \%$ and $46 \%$ of all contestants. There appears to be no evidence of nonlinear probability weighting or disappointment aversion. Observed decisions are generally consistent with the assumption of regret aversion and there is strong evidence for the fanning-out hypothesis. Nevertheless, we find no behavioral patterns that cannot be reconciled within the expected utility framework (or prospective reference theory that gives identical predictions).
\end{abstract}

Key words: decision theory, natural experiment, television show, expected utility, nonexpected utility

JEL Classification codes: C93, D81

\footnotetext{
${ }^{*}$ We are grateful to Wolfgang Köhler and participants of research seminars at the University of Zurich (April 6, 2006) and the University of Innsbruck (May 4, 2006) for their insightful comments. The second author acknowledges financial support from the Center for Experimental Economics at the University of Innsbruck (sponsored by Raiffeisen-Landesbank Tirol).

${ }^{\dagger}$ Corresponding author, Institute for Empirical Research in Economics, University of Zurich, Winterthurerstrasse 30, CH-8006 Zurich, Switzerland, tel.: +41(0)446343586, fax: +41(0)446344978, e-mail: pavlo.blavatskyy@iew.unizh.ch

* University of Innsbruck, Department of Economics, Institute of Public Finance, Universitätstrasse 15/4, A - 6020 Innsbruck, Austria, tel.: +43 (0)5125077148, email: ganna.pogrebna@uibk.ac.at
} 


\section{Testing the Predictions of Decision Theories in a Natural Experiment When Half a Million Is at Stake}

\section{Introduction}

Well-known violations of expected utility theory such as the Allais paradox (e.g. Allais, 1953) motivated the development of numerous generalized non-expected utility theories (e.g. Starmer, 2000). The merits of these decision theories were largely assessed according to their goodness of fit to the behavioral patterns observed in the laboratory experiments (e.g. Harless and Camerer, 1994; Hey and Orme, 1994). In this paper we test the predictions of ten decisions theories in a natural experiment with a more representative subject pool (drawn from the adult population of Italy) and significantly higher monetary incentives (prizes of up to half a million euros) than in conventional laboratory experiments.

In the television show Affari Tuoi (Italian version of Deal or No Deal), contestants make several choices between a risky lottery and an amount for certain. Risky lotteries, which contestants face in the show, are determined by chance events. This allows us to divide contestants across randomized treatments. Given an individual, whose preferences are described by a particular decision theory, we construct a treatment where she faces relatively unattractive lotteries (higher likelihood of choosing a sure amount) and a treatment where she faces relatively attractive lotteries (higher likelihood of choosing a risky lottery). By comparing behavioral patterns across two treatments, we test the predictions of decision theories without making any assumptions about their parametric forms.

Natural experiments, provided by television shows, are often used in economic research to draw conclusions about various aspects of human behavior. Television shows provide an appealing material for economists, because these shows are often structured as strategic games and well-defined decision problems (Metrick, 1995). For example, 
Bennett and Hickman (1993) and Berk, Hughson and Vandezande (1996) employ the natural laboratory of The Prize is Right to test for optimal information updating and rational bidding strategies correspondingly. Levitt (2004) and Antonovics, Arcidiancono and Walsh (2005) examine discrimination in The Weakest Link. Gertner (1993), Metrick (1995), and Beetsma and Schotman (2001) measure individual risk attitudes in the television shows Card Sharks, Jeopardy! and Lingo respectively.

Due to its simple design and high monetary incentives, the television show Deal or No Deal has attracted economists as a perfect laboratory for studying individual decision making under risk. Post et al. (2004) analyze risk attitudes of Belgian, Dutch and German Deal or No Deal contestants. Bombardini and Trebbi (2005) elicit risk attitudes of Affari Tuoi contestants. Mulino et al. (2006) and de Roos and Sarafidis (2006) measure risk attitudes and study the endowment effect in the Australian version of Deal or No Deal. In contrast to this paper, all these studies conduct a parametric estimation of expected utility theory by assuming that all contestants exhibit constant relative or absolute risk aversion. ${ }^{4}$ In a separate paper, Blavatskyy and Pogrebna (2006), we study the decisions of Affari Tuoi contestants, when they can exchange two ex ante identical risky lotteries, and find that contestants do not appear to be predominantly loss averse.

The remainder of this paper is organized as follows. Section 2 describes the rules of the television show Affari Tuoi. Section 3 presents the data generated in this natural experiment and demographic characteristics of Affari Tuoi contestants. The predictions of ten well-known decision theories are tested in section 4 . Section 5 concludes.

\footnotetext{
${ }^{4}$ In addition to expected utility theory, several of these studies also consider one generalized non-expected utility theory. Post et al. (2004) estimate a parametric form of cumulative prospect theory with so-called Quiggin's probability weighting function and an ad hoc reference point. Bombardini and Trebbi (2005) estimate a parametric form of (original) prospect theory with power probability weighting function and zero reference point. De Roos and Sarafidis (2006) estimate a parametric form of rank-dependent expected utility theory with power probability weighting function.
} 


\section{Description of the Television Show}

Affari Tuoi is the Italian version of the well-known Endemol television show Deal or No Deal. It is aired six days a week with an exception of Sunday on the first channel of Italian television RAI Uno. In order to become a contestant, interested candidates have to call a countrywide selection center. In other words, all contestants self-select into the show. According to Bombardini and Trebbi (2005), contestants are selected from the pool of interested candidates based on two criteria: entertaining appearance and income (wealthy candidates are discarded).

Twenty contestants, all representing different administrative regions of Italy, participate in every television episode. Contestants are randomly assigned sealed boxes, numbered consecutively from 1 to 20 . Each box contains one of twenty monetary prizes ranging from $€ 0.01$ to $€ 500,000$. The list of possible prizes is presented in Figure 1. An independent notary company allocates prizes across the boxes and seals the boxes.

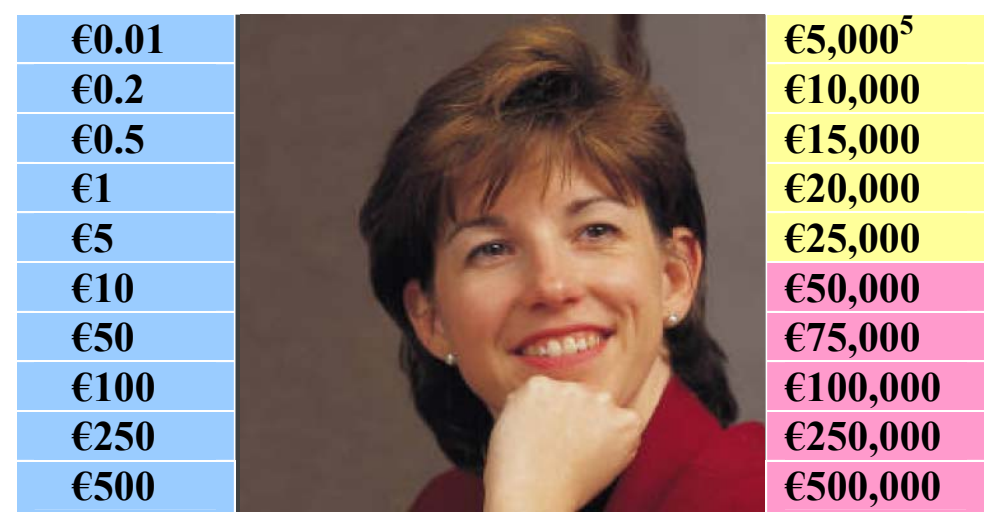

Figure 1 A typical screenshot with a list of possible prizes at the beginning of the game

Contestants know the list of potential prizes, that could be won during the game (i.e. Figure 1), but they do not know the content of each box. In every episode four small monetary prizes, ranging from $€ 0.01$ to $€ 500$, are substituted with token gifts, such as, for example, an orange instead of $€ 0.20$ or a puppy instead of $€ 100$. This substitution is done

\footnotetext{
${ }^{5}$ Prize $€ 5000$ was replaced with prize $€ 30000$ starting from January 30, 2006
} 
primarily for entertainment purposes and any contestant can reject a token gift and opt for its monetary equivalent.

Every television episode consists of two phases - the selection phase and the game itself. During the selection phase, contestants receive one multiple-choice general knowledge question. The contestant, who is the first to answer this question correctly, is selected to play the game. ${ }^{6}$ During the game, the contestant keeps her own box and opens the remaining boxes one by one. Once a box is opened, the prize sealed inside is publicly revealed and deleted from the list of possible prizes shown on Figure 1.

The more boxes the contestant opens, the more information she obtains about the distribution of possible prizes inside her own box. After opening several boxes the contestant receives an offer from the "bank". This offer could be either a monetary price for the content of her box or the possibility to exchange her box for any of the remaining sealed boxes. ${ }^{7}$ Figure 2 shows the timing of "bank" offers.

"Bank" monetary offers are fairly predictable across the episodes and follow a general pattern. In the early stages of the game, they are smaller than the expected value of possible prizes. As the game progresses, the gap between the expected value and the monetary offer decreases and often disappears when there are two unopened boxes left. A detailed regression analysis of "bank" monetary offers is presented in the next subsection. The game terminates when either the contestant accepts the price offered by the "bank" or when all boxes are opened. In the latter case, the contestant leaves with the content of her box, which is opened last.

\footnotetext{
${ }^{6}$ The remaining 19 contestants continue to participate in the next television episode. The contestant who was selected to play the game is replaced by a new contestant from the same region. The new contestant is selected from a pool of volunteers who called the selection center.

${ }^{7}$ Official rules of the show require the "bank" to offer exchange option at least once in every television episode. Therefore, the first offer that the "bank" makes is always the exchange offer. Before February 9, 2006, the first offer was always made after the contestant opened six boxes. Starting from February 9 , 2006, the first offer was made after the contestant opened three boxes.
} 


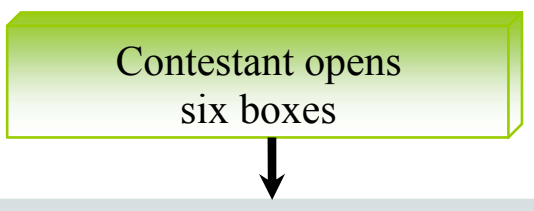

"Bank" offers to exchange her own box for any of 13 remaining unopened boxes

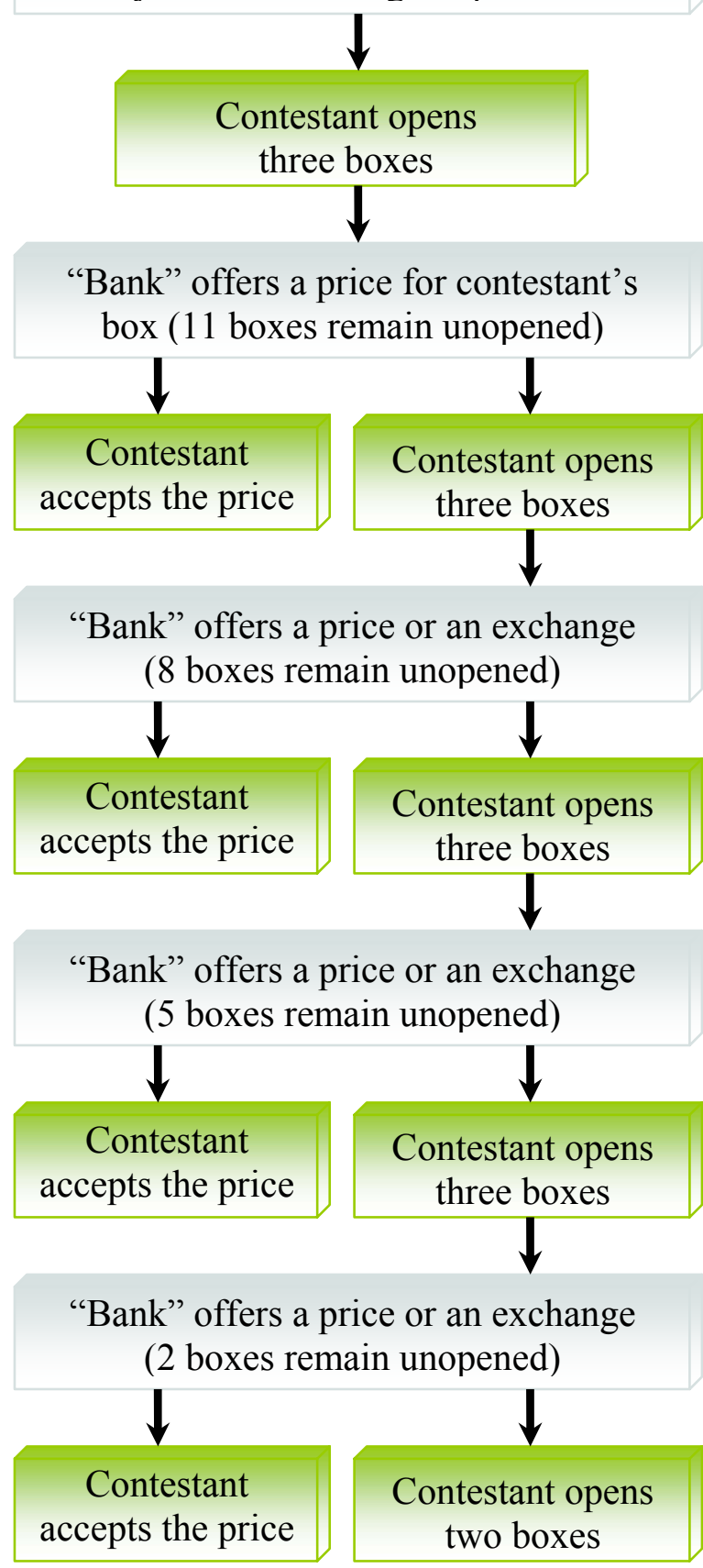

Contestant opens three boxes

"Bank" offers to exchange her own box for any of 16 remaining unopened boxes

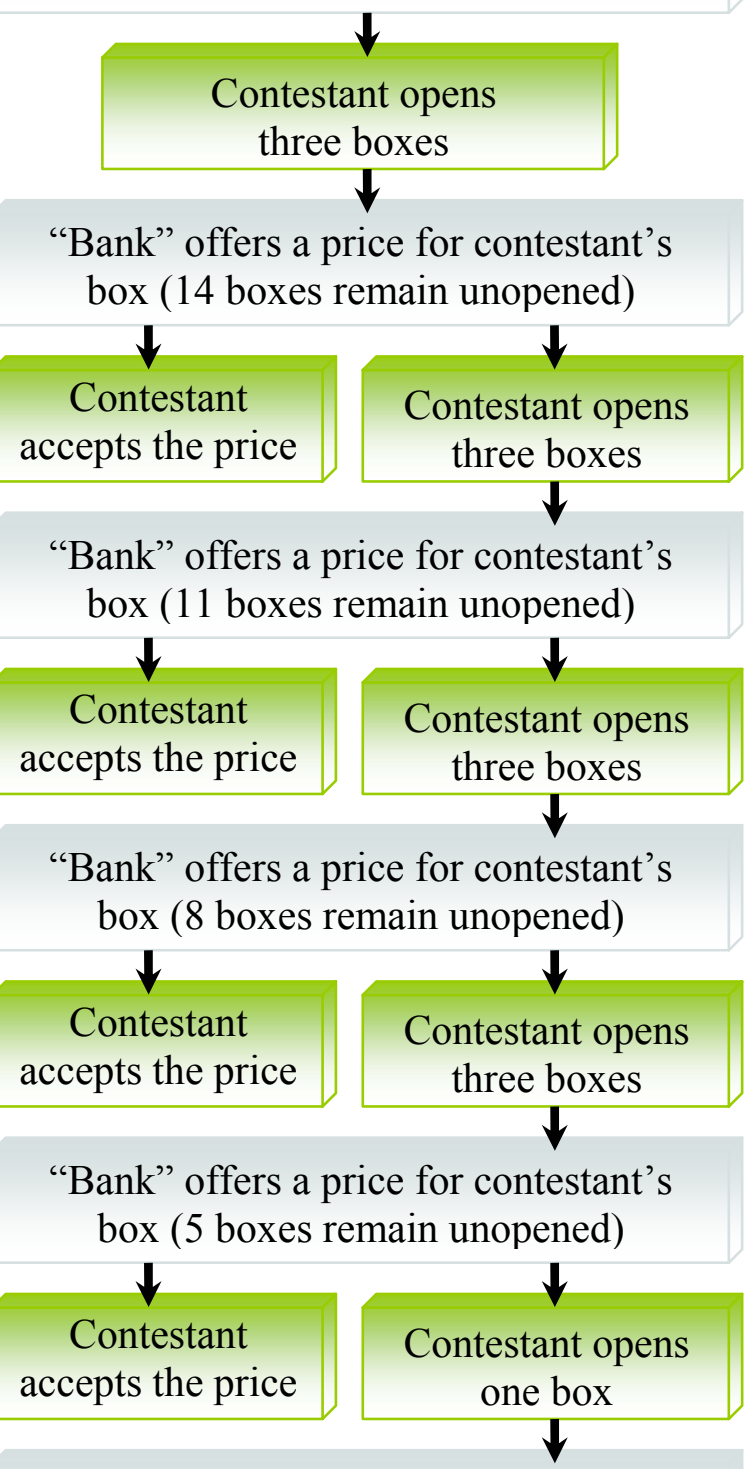

"Bank" offers a price or an exchange (if there are at least two unopened boxes)

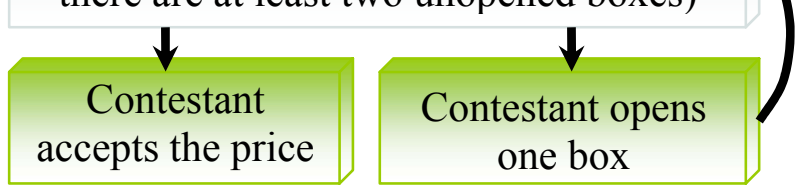

Figure 2 Timing of "bank" offers in television episodes before February 9, 2006 (left chart) and starting from February 9, 2006 (right chart) 


\section{Data}

The data, analyzed in this paper, were transcribed from original RAI Uno broadcasts of the television show Affari Tuoi from September 20, 2005 to March 4, 2006. The resulting natural laboratory contained 114 television episodes. Only one contestant played the game in every episode. This contestant had to decide on at least one exchange offer and at least one monetary offer. ${ }^{8}$ We recorded the distribution of all possible prizes that a contestant could potentially win at the moment when she made each decision as well as the prize sealed inside her own box (which was revealed only at the end of the show).

In the beginning of each television episode, the contestant, who was selected to play the game, states her name, place of current residence, marital status and, less often, age and occupation. In our dataset, contestants from every Italian region played the game at least once (e.g. Figure 3). Representatives of Lombardia played the game most frequently (10 times), while a contestant from Campania played the game only once.

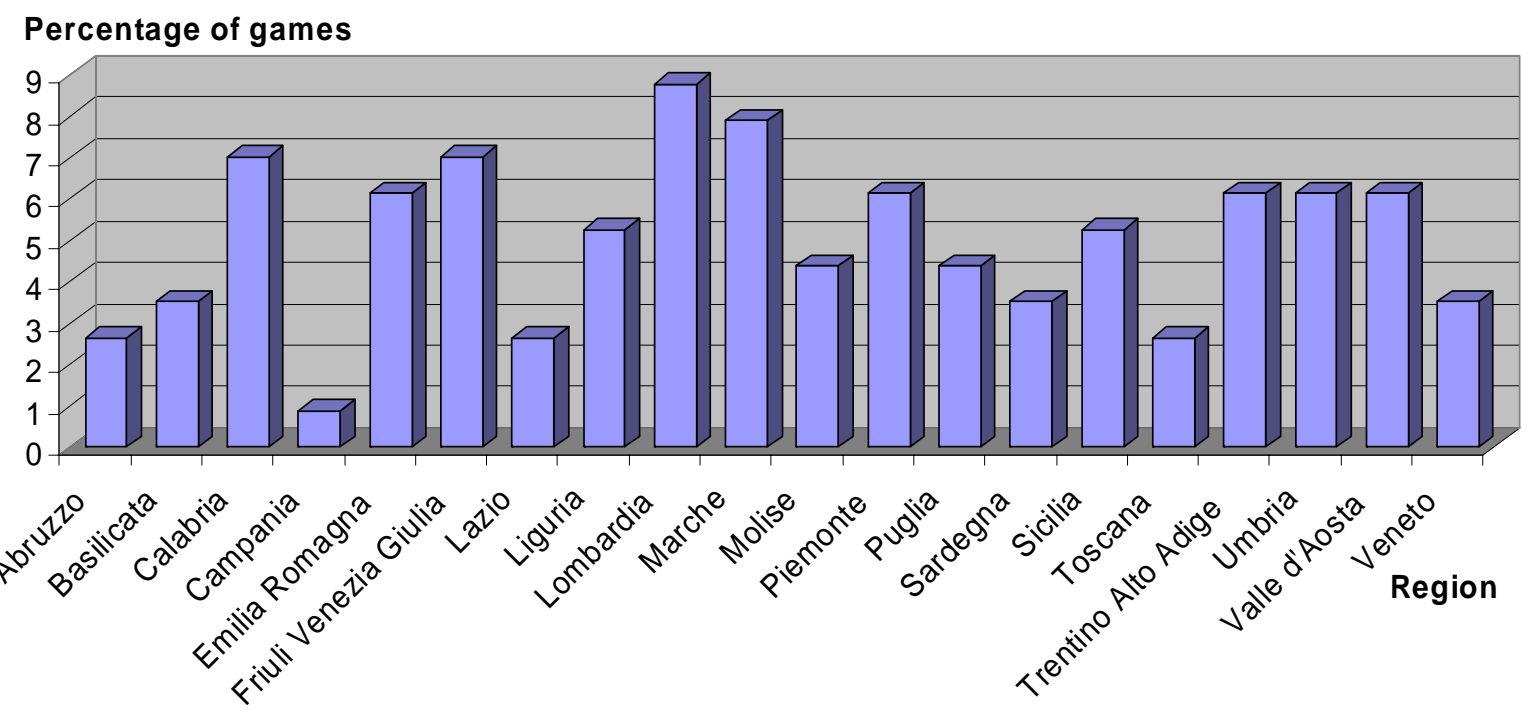

Figure 3 Regional distribution of contestants

\footnotetext{
${ }^{8}$ In our recorded sample only one contestant accepted the first monetary offer from the "bank" (€18 000). Ten contestants accepted the second monetary offer that they received from the "bank". 34 contestants accepted their third monetary offer. All remaining contestants received from 4 to 7 monetary offers.
} 
According to their self-reported data, Affari Tuoi contestants greatly varied in their age. The youngest contestant in our sample was 23 and the oldest was 70 years old. In terms of the gender composition, the share of female contestants (54\%) was slightly higher than that of male contestants (46\%). $79 \%$ of all contestants were married, $14 \%-$ single, $5 \%$ - divorced and $2 \%$ - widowed. Therefore, the demographics, age and personal characteristics of Affari Tuoi contestants make them a more representative subject pool than standard pools, composed primarily of undergraduate students. Moreover, obtaining a similar dataset in conventional laboratory conditions would be a highly ambitious project, since it would require a budget of $€ 3,364,852$.

Potentially, in Affari Tuoi any contestant can earn a maximum prize of $€ 500,000$. However, no contestant in our sample managed to win $€ 500,000$. The minimum prize earned in television episodes from September 20, 2005 to March 4, 2006 was $€ 0.01$ and the maximum prize was $€ 250,000$. The distribution of final earnings across the 114 television episodes in our sample is shown on Figure 4.

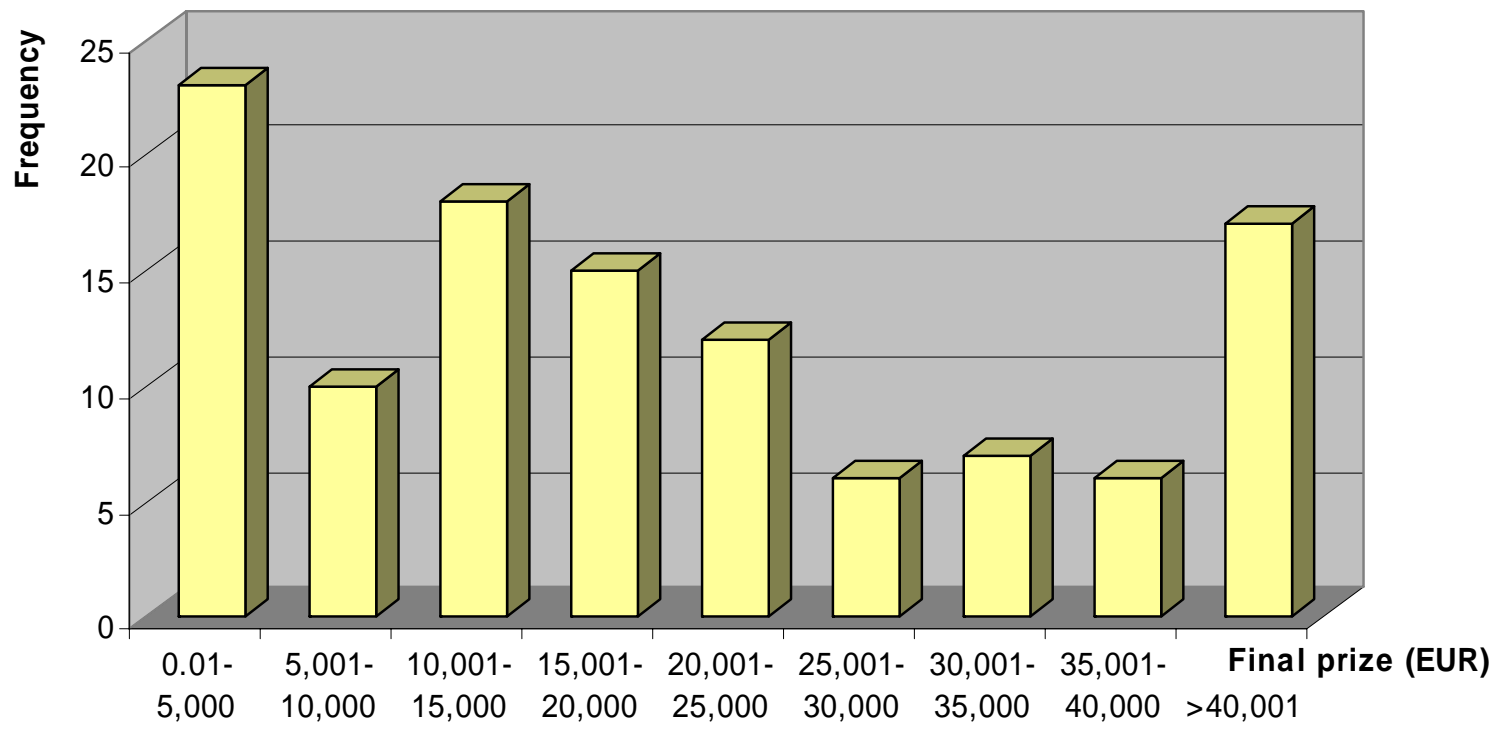

Figure 4 The distribution of final earnings across 114 episodes 
The average earnings of contestants were $€ 29,516$, with a median of $€ 19,000$ and a standard deviation of $€ 42,120$. Men earned on average $€ 3,798$ more than women. The standard deviation for final prizes, received by men, was $€ 11,780$ higher than that for final prizes that were won by women. While median earnings received by male contestants were $€ 20,000$, median earnings of females were $€ 17,000$. However, irrespective of the gender, average earnings in the show were significantly lower than the ex ante expected value of the prizes from Figure $1(€ 52,295)$.

Furthermore, average earnings were also lower than the average prize in the boxes, initially assigned to contestants who played the game. Figure 5 presents the distribution of monetary prizes in these boxes across 114 television episodes. This distribution is not significantly different from a uniform distribution $\left(\chi^{2}=22.49\right.$, $p=0.2605$ ). On average, contestants were endowed with $€ 41,279$ and the median initial endowment was $€ 250$.

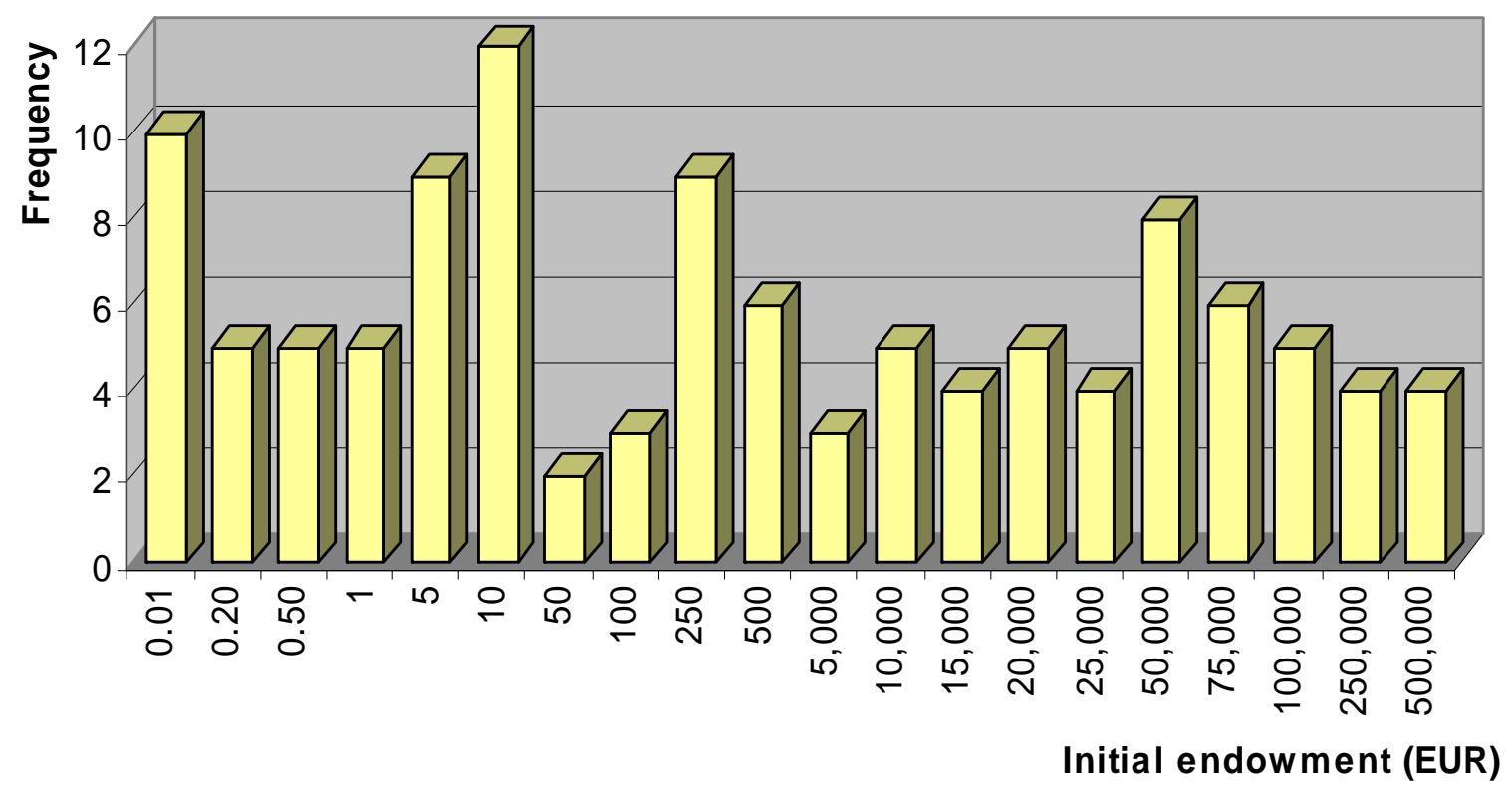

Figure 5 The distribution of initial endowments across 114 episodes 


\section{1. "Bank" monetary offers}

A precise mechanism of setting "bank" monetary offers is not revealed in show regulations. Bombardini and Trebbi (2005) suggest that offers in Affari Tuoi can be modeled as informative signals about the prize sealed inside a contestant's box that the "bank" sends to the contestant. De Roos and Sarafidis (2006) conduct a regression analysis of "bank" offers in the Australian version of Deal or No Deal and find that the variability in "bank" offers is largely explained by the expected value of the remaining prizes but not by the prize hidden inside a contestant's briefcase. Given these different models of "bank" offers suggested in the literature, we investigate the determinants of "bank" offers in our recorded sample.

Table 1 presents the results of ordinary least squares (OLS) regression $\ln \mathbf{O}=\beta_{0}+\beta_{1} \mathbf{X}_{1}+\ldots+\beta_{20} \mathbf{X}_{20}+\boldsymbol{\varepsilon}$ of 402 monetary amounts $O$ that the "bank" offered in exchange for risky lotteries in our recorded sample. Explanatory variables $\mathbf{X}_{1}, \ldots, \mathbf{X}_{20}$ consist of lottery specific variables (mean, median, and standard deviation of possible prizes etc.), socio-demographic characteristics of the contestants (gender, age, marital status and region) and treatment specific variables that are included to verify that the "bank" does not discriminate between different treatments that we consider in section 4 .

The second column of Table 1 demonstrates that around $85 \%$ of total variability in monetary offers is explained by the expected value and the number of possible prizes left. The "bank" makes higher offers when the number of possible prizes decreases, i.e. the game approaches the end. Regression coefficient on the standard deviation of possible prizes is also significant (the more dispersed are the prizes, the lower is the offer). However, regression coefficient of the prize hidden inside a contestant's box is never statistically significant, i.e. there is no information content in the "bank" offers. 


\begin{tabular}{|c|c|c|c|c|}
\hline \multirow{2}{*}{$\begin{array}{c}\text { Description of explanatory variable } \\
\text { Lottery specific variables: }\end{array}$} & \multicolumn{4}{|c|}{ Regression coefficient (standard error) } \\
\hline & & & & \\
\hline Constant & $\begin{array}{l}-0.4982^{*} \\
(0.2078)\end{array}$ & $\begin{array}{c}-0.7219^{* * *} \\
(0.2085)\end{array}$ & $\begin{array}{l}-0.6037^{*} \\
(0.2434)\end{array}$ & $\begin{array}{l}-0.697^{*} \\
(0.3426)\end{array}$ \\
\hline $\begin{array}{l}\text { Natural logarithm of expected value of } \\
\text { possible prizes }\end{array}$ & \begin{tabular}{|l}
$0.9956^{* * *}$ \\
$(0.0205)$ \\
\end{tabular} & $\begin{array}{l}1.5026^{* * *} \\
(0.1184) \\
\end{array}$ & \begin{tabular}{|l}
$1.5036^{* * *}$ \\
$(0.1189)$ \\
\end{tabular} & $\begin{array}{l}1.6057^{* * *} \\
(0.1526)\end{array}$ \\
\hline $\begin{array}{l}\text { Natural logarithm of a median possible } \\
\text { prize }\end{array}$ & & $\begin{array}{c}0.0132 \\
(0.0160)\end{array}$ & $\begin{array}{c}0.013 \\
(0.0161)\end{array}$ & $\begin{array}{c}0.0216 \\
(0.0192)\end{array}$ \\
\hline $\begin{array}{l}\text { Natural logarithm of standard deviation } \\
\text { of possible prizes }\end{array}$ & & $\begin{array}{c}-0.5073^{* * *} \\
(0.1055) \\
\end{array}$ & $\begin{array}{c}-0.5091^{* * * *} \\
(0.1058) \\
\end{array}$ & $\begin{array}{c}-0.6087^{* * * *} \\
(0.1384) \\
\end{array}$ \\
\hline $\begin{array}{l}\text { Natural logarithm of the prize hidden } \\
\text { inside a contestant's box }\end{array}$ & & $\begin{array}{c}0.0044 \\
(0.0063)\end{array}$ & $\begin{array}{c}0.0032 \\
(0.0064)\end{array}$ & $\begin{array}{c}0.0065 \\
(0.0065)\end{array}$ \\
\hline Number of possible prizes in a lottery & $\begin{array}{c}-0.0931^{* * *} \\
(0.0098) \\
\end{array}$ & $\begin{array}{l}-0.051^{* * *} \\
(0.0119) \\
\end{array}$ & $\begin{array}{c}-0.0515^{* * *} \\
(0.0119) \\
\end{array}$ & $\begin{array}{l}-0.0221 \\
(0.0252) \\
\end{array}$ \\
\hline \multicolumn{5}{|l|}{ Individual specific variables: } \\
\hline Gender dummy ( 0 - female, 1 - male) & & & $\begin{array}{c}0.0684 \\
(0.0601)\end{array}$ & $\begin{array}{c}0.0395 \\
(0.0611)\end{array}$ \\
\hline $\begin{array}{l}\text { Self-reported age (in years) or estimate } \\
\text { based on physical appearance }\end{array}$ & & & $\begin{array}{c}-0.002 \\
(0.0027) \\
\end{array}$ & $\begin{array}{l}-0.0021 \\
(0.0027)\end{array}$ \\
\hline $\begin{array}{l}\text { Marital status }(0-\text { married, } 1-\text { single, } \\
2 \text { - divorced, and } 3 \text { - widowed) }\end{array}$ & & & $\begin{array}{c}0.0324 \\
(0.0477)\end{array}$ & $\begin{array}{l}0.0383 \\
(0.479)\end{array}$ \\
\hline $\begin{array}{l}\text { Region dummy ( } 0 \text { for the region with } \\
\text { the lowest income per capita (Calabria), } \\
19 \text { for the highest (Lombardia) }\end{array}$ & & & $\begin{array}{l}-0.0044 \\
(0.0050)\end{array}$ & $\begin{array}{l}-0.0073 \\
(0.0051)\end{array}$ \\
\hline \multicolumn{5}{|l|}{ Treatment specific variables: } \\
\hline $\begin{array}{l}\text { Number of foregone prizes greater or } \\
\text { equal to } € 5000 \text { (in the last three boxes) }\end{array}$ & & & & $\begin{array}{l}-0.0351 \\
(0.0470)\end{array}$ \\
\hline $\begin{array}{l}\text { Number of foregone prizes that were } \\
\text { among three highest ranked prizes }\end{array}$ & & & & $\begin{array}{l}-0.0509 \\
(0.0596) \\
\end{array}$ \\
\hline Dummy for group 1 & & & & $0.2525^{*}(0.1187)$ \\
\hline Dummy for group 2 & & & & \begin{tabular}{|l|l|}
$-0.193(0.1053)$ \\
\end{tabular} \\
\hline Dummy for group 3 & & & & \begin{tabular}{|l}
$0.0645(0.0959)$ \\
\end{tabular} \\
\hline Dummy for group 4 & & & & $-0.0866(0.0937)$ \\
\hline Dummy for group 5 & & & & $0.0586(0.1016)$ \\
\hline Dummy for group 6 & & & & $0.0601(0.1013)$ \\
\hline Chances of $€ 500$ or less & & & & $0.06(0.2158)$ \\
\hline Number of prizes less or equal to $€ 5$ & & & & \begin{tabular}{|l}
$-0.0596(0.0395)$ \\
\end{tabular} \\
\hline $\mathbf{R}^{2}$ & 0.8567 & 0.8693 & 0.8703 & 0.8752 \\
\hline Adjuested $\mathbf{R}^{2}$ & 0.8560 & 0.8676 & 0.8673 & 0.8690 \\
\hline
\end{tabular}

${ }_{* * *}^{*}$ significant at 5\% significance level

*** significant at $0.1 \%$ significance level

Table 1 OLS regression results for "bank" monetary offers (dependent variablenatural logarithm of a price offered by the "bank"), $N=402$ 


\section{Testing Predictions of Decision Theories}

The predictions of ten well-known decision theories are tested in the natural experiment provided by the television show Affari Tuoi. We selected a typical menu of decision theories that are usually considered in existing studies that investigate which model of risky choice describes best the behavioral patterns observed in the conventional laboratory experiments (e.g. Table 2). Since every Affari Tuoi contestant makes only few observed choice decisions, we use a between-subject design to test the predictions of the selected decision theories (except for risk neutrality and the assumption of loss aversion of prospect theory that can be tested for every contestant). This paper follows a nonparametric approach, i.e. we do not make any assumptions about specific functional forms for utility functions, probability weighting functions etc.

\begin{tabular}{|l|c|c|c|c|c|}
\hline \multirow{2}{*}{\multicolumn{1}{c|}{ Decision theory }} & \multicolumn{5}{c|}{ Investigated in experimental study? } \\
\cline { 2 - 6 } & $\begin{array}{l}\text { Camerer } \\
(1989)\end{array}$ & $\begin{array}{l}\text { Starmer } \\
(1992)^{9}\end{array}$ & $\begin{array}{l}\text { Harless \& } \\
\text { Camerer } \\
(1994)^{9}\end{array}$ & $\begin{array}{l}\text { Hey and } \\
\text { Orme } \\
(1994)\end{array}$ & $\begin{array}{l}\text { Hey } \\
(2001)\end{array}$ \\
\hline Risk Neutrality & & & $\checkmark$ & $\checkmark$ & $\checkmark$ \\
\hline Expected Utility Theory & $\checkmark$ & $\checkmark$ & $\checkmark$ & $\checkmark$ & $\checkmark$ \\
\hline Weighted Utility Theory & $\checkmark$ & $\checkmark$ & $\checkmark$ & $\checkmark$ & $\checkmark$ \\
\hline Skew-Symmetric Bilinear Utility & $\checkmark$ & $\checkmark$ & $\checkmark$ & & \\
\hline (Cumulative) Prospect Theory & $\checkmark$ & $\checkmark$ & $\checkmark$ & & \\
\hline Regret Theory & & & & $\checkmark$ & \\
\hline Rank-Dependent Expected Utility & $\checkmark$ & $\checkmark$ & $\checkmark$ & $\checkmark$ & $\checkmark$ \\
\hline Yaari's Dual Model & & & $\checkmark$ & $\checkmark$ & \\
\hline Prospective Reference Theory & & & & $\checkmark$ & $\checkmark$ \\
\hline Disappointment Aversion Theory & & & $\checkmark$ & $\checkmark$ & $\checkmark$ \\
\hline
\end{tabular}

Table 2 Decision theories investigated in the existing laboratory experiments

\footnotetext{
${ }^{9}$ Similar to our study, Starmer (1992) and Harless \& Camerer (1994) tested fanning out hypothesis of weighted utility and skew-symmetric bilinear utility theory.

${ }^{10}$ Hey and Orme (1994) also considered the quadratic utility model of Chew et al. (1991) that is derived from a mixture symmetry axiom. However, there appears to be no testable implication of this theory in the context of this natural experiment.
} 


\subsection{Risk Neutrality}

Risk neutrality is arguably the simplest decision theory. A risk neutral individual always prefers the lottery with the highest expected value of possible outcomes. Formally, an individual chooses a risky lottery $L\left(x_{1}, 1 / n ; \ldots ; x_{n}, 1 / n\right)$ that delivers outcome $x_{i}, i \in\{1, \ldots, n\}$, with probability $1 / n$ over a sure amount $y$ if $\frac{1}{n} \sum_{i=1}^{n} x_{i} \geq y$.

In our sample of 114 Affari Tuoi episodes the "bank" made 402 monetary offers. Only two monetary offers exceeded the expected value of the prizes that a contestant was still able to win when the offer was made (one of these offers was accepted and one was rejected). ${ }^{11}$ Nine monetary offers were exactly equal to the expected value of possible prizes ( 4 were accepted and 5 were rejected). The overwhelming majority (391) of "bank" monetary offers was below the expected value of possible prizes (62 of these offers were accepted and 329 were rejected). ${ }^{12}$ Thus, 63 Affari Tuoi contestants (55.3\%) violated the assumption of risk neutrality, i.e. 62 contestants accepted "bank" offers lower than the expected value and 1 contestant rejected a "bank" offer higher than the expected value.

\subsection{Expected Utility Theory}

According to expected utility theory, an individual evaluates monetary outcomes by means of a subjective utility function and chooses the lottery with the highest expected utility of possible outcomes. Formally, an individual chooses a risky lottery

\footnotetext{
${ }^{11}$ It appears that these two more than actuarially fair offers resulted from rounding of "bank" offers and they do not reflect a systematic policy of the "bank" to make occasional "kind" offers. On one occasion, the "bank" offered $€ 40$ when the expected value of three remaining prizes was $€ 36.83$ and on the second occasion the "bank" offered $€ 17000$ when the expected value of eight remaining prizes was $€ 16300$.

${ }^{12}$ Due to rounding of "bank" offers, several offers were just few pennies below the expected value of outstanding prizes. For example, seven offers were less than $1 \%$ below the expected value of possible prizes and the contestants rejected six of these offers. Thus, a large number of accepted less than actuarially fair offers cannot be explained by the fact that some of these offers were just marginally lower than the expected value of possible prizes.
} 
$L\left(x_{1}, 1 / n ; \ldots ; x_{n}, 1 / n\right)$ over a sure amount $y$ if $\frac{1}{n} \sum_{i=1}^{n} u\left(x_{i}\right) \geq u(y)$, where $u: \mathrm{R} \rightarrow \mathrm{R}$ is a

(Bernoulli) utility function over money. The utility function can be normalized without loss of generality for two outcomes, e.g. $u(0.01 €)=0$ and $u(500000 €)=1$.

Before February 9, 2006 every Affari Tuoi contestant received up to 4 monetary offers for a distribution of up to 11 possible prizes. Starting from February 9, 2006 Affari Tuoi contestants receive up to 7 monetary offers and the first offer is made for a distribution of 14 possible prizes. Obviously, a non-parametric test of expected utility theory is not feasible on Affari Tuoi data because every contestant makes only few observed decisions but faces lotteries with many outcomes. ${ }^{13}$ Therefore, instead of testing the prediction of expected utility theory, we look for patterns in the data that are difficult to reconcile within the expected utility framework.

Expected utility maximizers take into account only the distribution of possible prizes, the current offer and the expectation of future "bank" offers. Thus, their decisions are not influenced by monetary prizes that were already eliminated from the list of possible prizes. However, Post et al. (2004) find that Deal or No Deal contestants from Belgium, Germany and the Netherlands tend to exhibit a lower coefficient of relative risk aversion after the elimination of large prizes. ${ }^{14}$ Given this finding, we test if Affari Tuoi contestants, who experienced recent elimination of large prizes, reject "bank" offers more often.

\footnotetext{
${ }^{13}$ For every contestant, there are at most only 7 weak inequalities restricting individual utility function and at least 9 outcomes, utility of which can be freely chosen (given that utility of two outcomes is normalized). ${ }^{14}$ Notice that this finding does not necessarily contradict to the expected utility theory. It rather shows that subjective utility function does not exhibit a constant coefficient of relative risk aversion. Instances, when a contestant rejects a more than actuarially fair offer only to accept later a less than actuarially fair offer, also do not necessarily contradict to the expected utility theory if utility function is concave over one range of outcomes and convex over another (e.g. Markowitz, 1952).
} 
Since the "bank" typically makes the next monetary offer after a contestant opens another three boxes, we consider if contestants' decision to accept or reject the offer depends on the number of large prizes that were discovered in the last three boxes opened prior to the decision. We define a large prize both in absolute terms (any prize higher or equal to $€ 5000{ }^{15}$ ) and in relative terms (three largest prizes in the distribution of possible prizes that the contestant faced before opening three boxes). Table 1 shows that "bank" monetary offers do not depend on the number of foregone large prizes, for large prizes in both absolute and relative terms. Table 3 shows how many Affari Tuoi contestants accepted and rejected "bank" monetary offers in both cases.

\begin{tabular}{|c|c|c|}
\hline $\begin{array}{l}\text { Number of } \\
\text { foregone } \\
\text { large prizes }\end{array}$ & \multicolumn{2}{|c|}{$\begin{array}{c}\text { Number (percentage) of } \\
\text { contestants who ... }\end{array}$} \\
\hline Accept offer & Reject offer \\
\hline $\mathbf{0}$ & $6(15.00 \%)$ & $34(85.00 \%)$ \\
\hline $\mathbf{1}$ & $30(16.39 \%)$ & $153(83.61 \%)$ \\
\hline $\mathbf{2}$ & $24(16.67 \%)$ & $120(83.33 \%)$ \\
\hline $\mathbf{3}$ & $7(20.00 \%)$ & $28(80.00 \%)$ \\
\hline
\end{tabular}

\begin{tabular}{|c|c|c|}
\hline \multirow{2}{*}{$\begin{array}{l}\text { Number of } \\
\text { foregone } \\
\text { large prizes }\end{array}$} & \multicolumn{2}{|c|}{$\begin{array}{c}\text { Number (percentage) of } \\
\text { contestants who ... }\end{array}$} \\
\hline $\mathbf{0}$ & $10(8.06 \%)$ & $114(91.94 \%)$ \\
\hline $\mathbf{1}$ & $35(18.04 \%)$ & $159(81.96 \%)$ \\
\hline $\mathbf{2}$ & $21(26.92 \%)$ & $57(73.08 \%)$ \\
\hline $\mathbf{3}$ & $1(16.67 \%)$ & $5(83.33 \%)$ \\
\hline
\end{tabular}

Table 3 Decisions of contestants depending on the number of large prizes discovered in the last three opened boxes. Large prizes are defined as prizes greater or equal to €5000 (left table) or three highest ranked prizes (right table).

For large prizes in absolute terms, the acceptance rate for "bank" offers does not depend on the number of foregone large prizes. For large prizes in relative terms, there is a significant difference in acceptance rates only between contestants who were lucky not to eliminate any of large prizes and contestants who eliminated two of the three highest ranked prizes when opening the last three boxes. ${ }^{16}$ Thus, there appears to be no evidence of path-dependence i.e. contestants' decisions being influenced by a foregone history.

\footnotetext{
${ }^{15}$ Figure 1 offers a natural threshold for distinguishing between large and small prizes. All prizes that are above or equal to $€ 5000$ are significantly (at least 10 times) higher than all prizes below $€ 5000$.

${ }^{16}$ Interestingly, Affari Tuoi contestants who eliminated several large prizes tend to accept "bank" offers more often than contestants who did not eliminate any of large prizes, which is the opposite of the effect reported in Post et al. (2004).
} 


\subsection{Fanning-Out (Weighted Utility Theory, Transitive Skew-Symmetric Bilinear Utility Theory)}

Machina (1982) proposed the fanning-out hypothesis that individuals do not

become less risk averse when lotteries improve in the sense of the first-order stochastic dominance. Several decision theories such as weighted utility theory (e.g. Chew and McCrimmon, 1979, Chew, 1983) and transitive skew-symmetric bilinear utility theory (e.g. Fishburn, 1983, 1988) incorporate the fanning-out hypothesis by restricting their general utility functionals to explain well-know violations of the expected utility theory such as the Allais paradox (e.g. Allais, 1953) or common ratio effect (e.g. Starmer, 2000).

To test the fanning-out hypothesis, we consider all Affari Tuoi contestants who received a monetary offer for a distribution of eight, five and two possible prizes ${ }^{17}$. In each of these three cases, we select a separating lottery and compare the acceptance (rejection) rate for "bank" offers in two groups of contestants. In the first group, contestants face a distribution of possible prizes, which is stochastically dominated by the separating lottery. In the second group, contestants face a distribution of possible prizes, which stochastically dominates the separating lottery. The separating lottery is selected to maximize the minimum number of observations in two groups ${ }^{18}$.

Contestants are allocated across the two groups at random (as a result of chance events). Table 1 shows that the "bank" does make higher offers to contestants in group 2.

\footnotetext{
${ }^{17}$ We do not consider contestants' decisions on monetary offers for a distribution of eleven possible prizes because such offer was accepted only by one contestant in our recorded sample.

${ }^{18}$ We obtained a separating lottery $(a, 1 / 2 ; b, 1 / 2), 10 €<a<50 €$ and $20000 €<b<25000 €$ for contestants who faced a distribution of two possible prizes, a separating lottery $(a, 1 / 5 ; b, 1 / 5 ; c, 1 / 5 ; d, 1 / 5 ; e, 1 / 5), 0.5 €<a<1 €, 50 €<b<100 €, 500 €<c<5000 €$, $20000 €<d<25000 €$ and $100000 €<e<250000 €$ for contestants who faced a distribution of five possible prizes, and a separating lottery $(a, 1 / 8 ; b, 1 / 8 ; c, 1 / 8 ; d, 1 / 8 ; e, 1 / 8 ; f, 1 / 8 ; g, 1 / 8 ; h, 1 / 8)$, $0.01 €<a<0.2 €, 1 €<b<5 €, 50 €<c<100 €, 250 €<d<500 €, 5000 €<e<10000 €$, $15000 €<f<20000 €, 50000 €<g<75000 €$ and $250000 €<h<500000 €$ for contestants who faced a distribution of eight possible prizes.
} 
In fact, at 5\% significance level we cannot reject the hypothesis that the "bank" makes higher offers to group 1 . This allows us to formulate our testing hypothesis as follows:

Hypothesis I Contestants in both groups accept "bank" offers equally often.

Hypothesis II (fanning out) Contestants in the second group accept monetary offers from the "bank" more often than contestants in the first group.

Contestants facing a distribution of 8 prizes

G1

G2

\begin{tabular}{|c|c|}
\multicolumn{1}{|c}{ YES } & NO \\
\hline 1 & 12 \\
\hline 3 & 12 \\
\hline \multicolumn{2}{c}{$N=28$}
\end{tabular}

Fisher's exact test (one sided) $p=0.3831$
Contestants facing a distribution of 5 prizes

\begin{tabular}{cc|c|}
\multicolumn{1}{c}{} & \multicolumn{1}{c}{ YES } & NO \\
\cline { 2 - 3 } G1 & 3 & 16 \\
\cline { 2 - 3 } G2 & 10 & 9 \\
\cline { 2 - 3 } & \multicolumn{3}{c}{$N=38$}
\end{tabular}

Fisher's exact test (one sided) $p=0.0191$

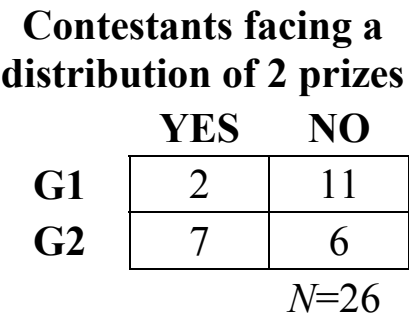

Fisher's exact test (one sided) $p=0.0484$

Table 4 Number of contestants accepting ("YES") and rejecting ("NO") "bank" offers in group 1 (G1) and group 2 (G2). All contestants in G2 face distributions that stochastically dominate distributions faced by contestants in G1.

Table 4 shows that the fraction of contestants who accept "bank" offers is always higher in the second group than in the first group. This difference is also statistically significant for contestants who face a distribution of five and two possible prizes. Thus, the data from our natural experiment strongly support the fanning-out hypothesis. Although this finding may cast doubt on the descriptive validity of expected utility theory, it does not necessarily contradict the expected utility framework. The reason is that contestants in groups 1 and 2 generally faced lotteries over different monetary prizes. Thus, expected utility maximizers with convex (or linear) utility function over small outcomes and concave utility function over large outcomes may also exhibit this type of fanning-out. Note that evidence of fanning-out that invalidates expected utility theory comes from conventional laboratory experiments where subjects face lotteries over the same outcomes (usually, three-outcome lotteries located inside the probability triangle). 


\section{4. (Cumulative) Prospect Theory}

According to prospect theory, an individual obtains a simplified representation of a decision problem in the editing phase and subsequently evaluates edited lotteries in the evaluation phase (e.g. Kahneman and Tversky, 1979). Two editing operations that are relevant in the context of this experiment are simplification (monetary outcomes are rounded up) and combination (probabilities associated with identical outcomes are added together). In the evaluation phase, edited lotteries are evaluates by means of an S-shaped value function and inverse-S shaped probability weighting function.

The value function satisfies the assumption of loss aversion-individuals derive a higher disutility from losses than utility from equal-sized gains. Gains and losses are measured relative to the reference point that "usually corresponds to the current asset position" (Kahneman and Tversky, 1979). The probability weighting function overvalues small probabilities and undervalues medium and high probabilities. Note that in cumulative prospect theory (e.g. Tversky and Kahneman, 1992) this effect holds only for extreme outcomes (highest ranked and lowest ranked gains and losses). We will test the rank-dependent nonlinear probability weighting in section 4.6 below.

A rather natural implication of the editing phase in the contest of this natural experiment is that Affari Tuoi contestants round up numerous small outcomes in the left section of Figure 1 and combine their probabilities in one joint probability. ${ }^{19}$ This joint probability is overweighted, if small, and underweighted otherwise. Thus, prospect theory predicts that Affari Tuoi contestants facing a low chance of receiving a small prize $(\leq € 500)$ are likely to accept "bank" offers more frequently than the contestants facing a high chance of ending up with $€ 500$ or less.

\footnotetext{
${ }^{19}$ Figure 1 also shows that prizes are framed in a way that encourages such editing. All small prizes in the left section are highlighted in one color (blue).
} 
Monetary offers for a distribution of eight possible prizes

\begin{tabular}{|c|c|c|}
\hline \multirow{2}{*}{$\begin{array}{l}\text { Chance of } \\
\boldsymbol{\epsilon} 500 \text { or less }\end{array}$} & \multicolumn{2}{|c|}{$\begin{array}{c}\text { Number (percentage) of } \\
\text { contestants who ... }\end{array}$} \\
\cline { 2 - 3 } & Accept offer & Reject offer \\
\hline $\mathbf{1 / 4}$ & $2(28.57 \%)$ & $5(71.43 \%)$ \\
\hline $\mathbf{3 / 8}$ & $1(2.63 \%)$ & $37(97.37 \%)$ \\
\hline $\mathbf{1 / 2}$ & $4(12.12 \%)$ & $29(87.88 \%)$ \\
\hline $\mathbf{5 / 8}$ & $3(11.54 \%)$ & $23(88.46 \%)$ \\
\hline $\mathbf{3 / 4}$ & $0(0.00 \%)$ & $3(100.00 \%)$ \\
\hline
\end{tabular}

Monetary offers for a distribution of five possible prizes

\begin{tabular}{|c|c|c|}
\hline \multirow{2}{*}{$\begin{array}{c}\text { Chance of } \\
\boldsymbol{E 5 0 0} \text { or less }\end{array}$} & \multicolumn{2}{|c|}{$\begin{array}{c}\text { Number (percentage) of } \\
\text { contestants who ... }\end{array}$} \\
\cline { 2 - 3 } & Accept offer & Reject offer \\
\hline $\mathbf{0}$ & $1(33.33 \%)$ & $2(66.67 \%)$ \\
\hline $\mathbf{1 / 5}$ & $7(35.00 \%)$ & $13(65.00 \%)$ \\
\hline $\mathbf{2} / \mathbf{5}$ & $10(35.71 \%)$ & $18(64.29 \%)$ \\
\hline $\mathbf{3 / 5}$ & $12(37.50 \%)$ & $20(62.50 \%)$ \\
\hline $\mathbf{4 / 5}$ & $4(30.77 \%)$ & $9(69.23 \%)$ \\
\hline
\end{tabular}

Table 5 Decisions of contestants and the chance of receiving a small prize $(\leq € 500)$

To test this prediction of prospect theory, we consider the decisions of Affari Tuoi contestants who received an offer for a distribution of eight and five possible prizes. ${ }^{20}$ Table 5 shows no evidence that low chances of a small prize are overweighted (leading to a higher acceptance rate) and high chances of a small prize are underweighted (leading to a lower acceptance rate). ${ }^{21}$ Only contestants who face a $1 / 4$ chance of receiving $€ 500$ or less are marginally more likely to accept "bank" offers than contestants who face a corresponding chance of $3 / 8$ (one sided Fisher's exact test $p=0.0587$ ).

Natural laboratory of Affari Tuoi can be also used for testing the assumption of loss aversion of prospect theory by considering the decisions of contestants who received an exchange offer. Particularly, Blavatskyy and Pogrebna (2006) show that loss averse contestants should always reject the exchange offer and keep the box that they are endowed with. However, $46 \%$ of all contestants violated the assumption of loss aversion (39\% accepted the first exchange offer and 7\% rejected the first exchange offer but accepted the second exchange offer).

\footnotetext{
${ }^{20}$ We do not consider the decisions of contestants who received a monetary offer for a distribution of eleven and two prizes because there is no sufficient variability of the data in the first case (only one contestant accepted a monetary offer for a distribution of eleven prizes) and contestants do not face outcomes of low probability in the second case.

${ }^{21}$ Similar results hold when only the probabilities of prizes below or equal to $€ 250, € 100$ etc. are combined.
} 


\subsection{Regret Theory (Non-Transitive Skew-Symmetric Bilinear Utility Theory)}

According to regret theory, an individual experiences regret (rejoicing) when a lottery that she has chosen delivers lower (higher) outcome than the ex post outcome of the lottery that she did not choose. Ex ante, an individual anticipates future regret or rejoicing and attempts to minimize ex post regret (e.g. Loomes and Sugden, 1987). Formally, an individual chooses a risky lottery $L\left(x_{1}, 1 / n ; \ldots ; x_{n}, 1 / n\right)$ over a sure amount $y$ if $\sum_{i=1}^{n} \psi\left(x_{i}, y\right) \geq 0$, where $\psi(\cdot$,$) is a skew-symmetric function satisfying the assumption$ of regret aversion: $\psi(a, c)>\psi(a, b)+\psi(b, c), \forall a>b>c$ (e.g. Loomes et al., 1992). Since contestants always choose between one risky and one degenerate lottery, i.e. between two statistically independent lotteries, regret theory also coincides with (nontransitive) skew-symmetric bilinear utility theory (e.g. Loomes and Sugden, 1987).

To test the prediction of regret theory, we consider all decisions of Affari Tuoi contestants when they reject a monetary offer from the "bank" (335 cases), when they accept a monetary offer for a distribution of two possible prizes (18 cases) and when they receive an offer to exchange their box for the only one remaining sealed box (23 cases). In all these cases it is easy to establish the outcome that a contestant would have experienced, if she had changed her decision. ${ }^{22}$ We consider the difference between final earnings of Affari Tuoi contestants and the outcome that they would have received if they had reached a different decision in 376 cases described above. A positive difference signifies rejoicing and a negative difference denotes regret.

\footnotetext{
${ }^{22}$ We do not consider the decisions of contestants to accept a monetary offer from the "bank", when more than two boxes remain unopened (49 cases), and the decisions of contestants when they receive exchange offer and more than two boxes remain unopened (125 cases). In these cases it is impossible to establish with certainty what outcome a contestant would have experienced, had she changed her decision.
} 
If the assumption of regret aversion holds, instances of ex post regret are likely to be infrequent and/or of a smaller absolute magnitude compared to the instances of ex post rejoicing. Affari Tuoi contestants indeed experienced regret only in 146 cases (38.8\%) compared to 211 cases (56.1\%) of rejoicing. ${ }^{23}$ Moreover, there are only few instances of a large regret and numerous cases of a large rejoicing. ${ }^{24}$ Figure 6 shows that cumulative distribution function of ex post rejoicing clearly (first order) stochastically dominates cumulative distribution function of ex post regret. Thus, Affari Tuoi contestants are quite successful in avoiding ex post regret, which is consistent with the assumption of regret aversion (convexity of a skew-symmetric utility function).

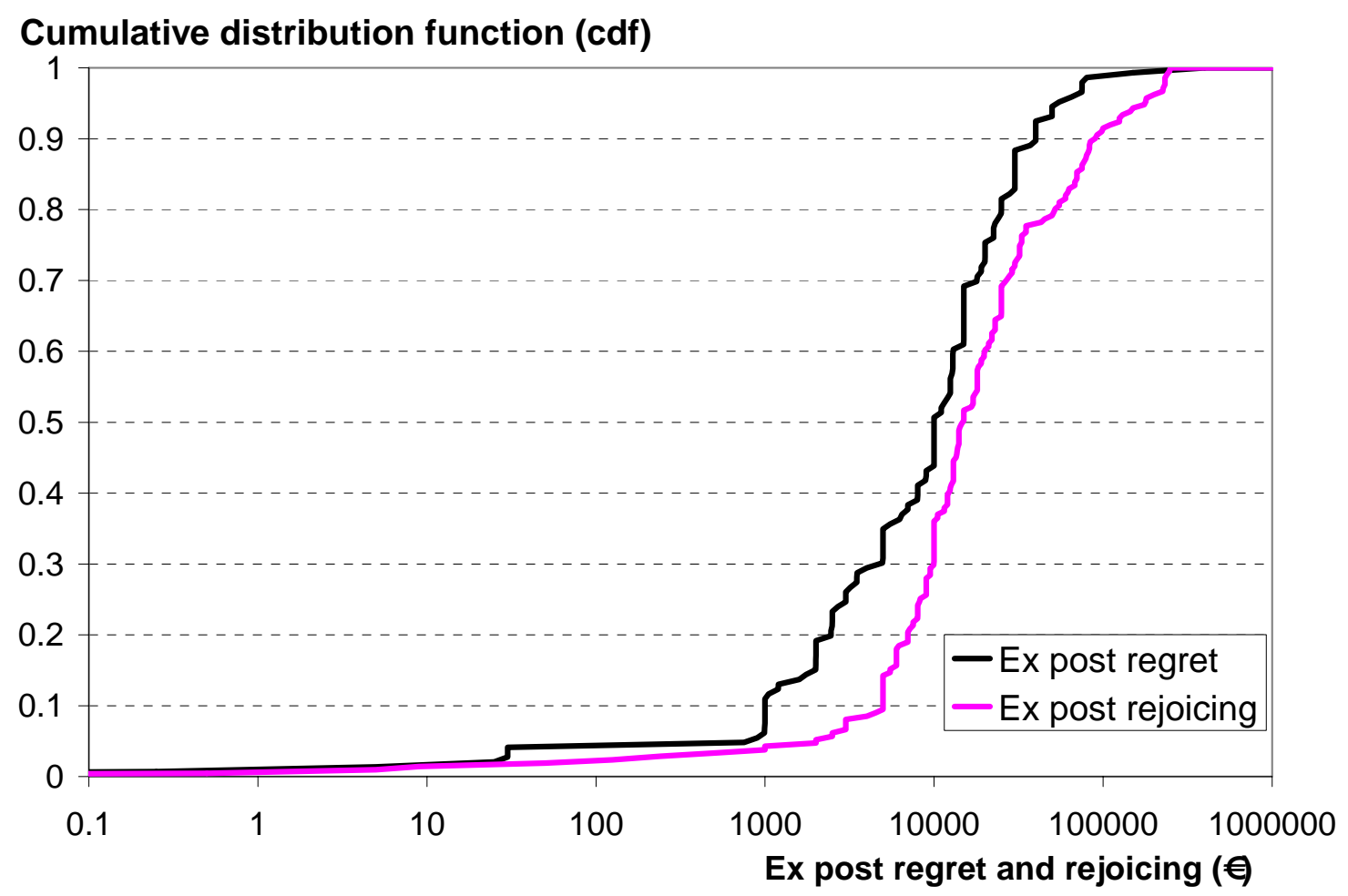

Figure 6 Cumulative distribution function of ex post regret (absolute amount) and ex post rejoicing. Vertical axis shows the probability that an Affari Tuoi contestant regretted for or rejoiced in an amount not higher than shown on the horizontal axis.

\footnotetext{
${ }^{23}$ In 19 cases $(5.1 \%)$ there was no regret and no rejoicing.

${ }^{24}$ For example, there are only 3 cases when contestants regretted loosing more than 75000 Euro (including one instance of a dramatic regret when a contestant could have won 400000 Euro more) and 29 cases when contestants rejoiced gaining more than 75000 Euro.
} 


\subsection{Rank-Dependent Expected Utility Theory}

According to rank-dependent expected utility theory, an individual chooses a risky lottery $L\left(x_{1}, 1 / n ; \ldots ; x_{n}, 1 / n\right), \quad x_{1}>x_{2}>\ldots>x_{n}$, over a sure amount $y$ if $\sum_{i=1}^{n}\left[w\left(\frac{i}{n}\right)-w\left(\frac{i-1}{n}\right)\right] \cdot u\left(x_{i}\right) \geq u(y)$, where $w:[0,1] \rightarrow[0,1]$ is a probability weighting function and $u: \mathrm{R} \rightarrow \mathrm{R}$ is utility function (e.g. Quiggin, 1982). The probability weighting function is strictly increasing and satisfies boundary conditions $w(0)=0$ and $w(1)=1$. Additionally, this function has a characteristic inverse-S shape-it is concave for low probabilities $(p<1 / 3)$ and convex for medium and high probabilities $(p>1 / 3)$. When all lottery outcomes $x_{1}>x_{2}>\ldots>x_{n}$ are above the reference point of an individual, the prediction of rank-dependent expected utility theory is identical to the prediction of cumulative prospect theory (e.g. Tversky and Kahneman, 1992).

The inverse-S shape of the probability weighting function implies that individuals overvalue small probabilities of extreme outcomes (i.e. highest ranked and lowest ranked outcomes) and undervalue medium and high probabilities of extreme outcomes. Consider an individual facing a risky lottery that delivers the highest possible outcome with a small probability and this outcome is significantly higher (in terms of utility) than the second highest possible outcome of a lottery. Rank-dependent expected utility theory predicts that the individual overvalues such a lottery, i.e. she is likely to exhibit risk-seeking behavior. Similarly, the individual undervalues a risky lottery that yields the lowest possible outcome with a small probability if this outcome is significantly lower (in terms of utility) than the second lowest possible outcome of a lottery. In this case an individual is more likely to exhibit risk-averse behavior. 
To test the predictions of rank-dependent expected utility theory, we consider the decisions of Affari Tuoi contestants who received a monetary offer for a distribution of eight and five possible prizes. ${ }^{25}$ These contestants face risky lotteries that yield every possible prize with probability 0.2 and 0.125 , respectively. We consider the acceptance/rejection rate for "bank" monetary offers across four groups of contestants. Contestants are divided across four groups depending on the risky lottery that they face:

Group 3 The highest possible prize of a lottery is at least ten times higher than the second highest prize of the lottery.

Group 4 The two highest possible prizes of a lottery are adjacent prizes (e.g. in Figure 1). If the lottery has eight possible prizes, the three highest ranked prizes are adjacent.

Group 5 The second lowest possible prize of a lottery is at least ten times higher than the lowest prize of the lottery.

Group 6 The two lowest possible prizes of a lottery are adjacent prizes (e.g. in Figure 1). If the lottery has eight possible prizes, the three lowest ranked prizes are adjacent. ${ }^{26}$

Table 1 shows that the "bank" does not discriminate between members of groups 3-6 when making monetary offers. Rank-dependent expected utility theory then predicts that "bank" offers are rejected more frequently in group 3 than in group 4. Probability of receiving a large prize is $20 \%$ or $12.5 \%$ in group 3 and $40 \%$ or $37.5 \%$ in group 4 . This probability is overweighed to a stronger extent in group 3 than in group $4,{ }^{27}$ leading to a higher rejection of "bank" offers. Similarly, rank-dependent expected utility theory predicts that "bank" offers are accepted more frequently in group 5 than in group 6.

\footnotetext{
${ }^{25}$ See footnote 20 .

${ }^{26}$ For identification of groups 5 and 6 , prizes $€ 0.01, € 0.20, € 0.50, € 1$ and $€ 5$ are treated as identical.

${ }^{27}$ For example a $1 / 5$ chance of a large prize $x_{1}$ is valued as $w(1 / 5) \cdot u\left(x_{1}\right)$, which can be higher than utility of an actuarially fair offer $u\left(x_{1} / 5\right)$ if $w(1 / 5)>1 / 5$. However a $1 / 5$ chance of $x_{1}$ and a $1 / 5$ chance of a similar large prize $x_{2}<x_{1}, u\left(x_{2}\right) \approx u\left(x_{1}\right)$, is valued as $w(1 / 5) \cdot u\left(x_{1}\right)+[w(2 / 5)-w(1 / 5)] \cdot u\left(x_{2}\right) \approx w(2 / 5) \cdot u\left(x_{1}\right)$, which is likely to be lower than utility of an actuarially fair offer $u\left(\left(x_{1}+x_{2}\right) / 5\right)$ if $w(2 / 5) \leq 2 / 5$.
} 
Monetary offers for a distribution of eight possible prizes:

\begin{tabular}{c|c|c|}
\multicolumn{1}{c}{} & \multicolumn{1}{c}{ Accepted } & Rejected \\
\cline { 2 - 3 } Group 3 & 1 & 11 \\
\cline { 2 - 3 } Group 4 & 0 & 14 \\
\cline { 2 - 3 } & &
\end{tabular}

Fisher's exact test (one sided) $p=0.9999$

\begin{tabular}{l|c|c|}
\multicolumn{1}{c}{} & \multicolumn{1}{c}{ Accepted } & Rejected \\
\cline { 2 - 3 } Group 5 & 2 & 16 \\
\cline { 2 - 3 } Group 6 & 4 & 49 \\
\cline { 2 - 3 } & &
\end{tabular}

Fisher's exact test (one sided) $p=0.4790$
Monetary offers for a distribution of five possible prizes:

\begin{tabular}{l|c|c|}
\multicolumn{1}{c}{} & \multicolumn{1}{c}{ Accepted } & \multicolumn{1}{c}{ Rejected } \\
\cline { 2 - 3 } Group 3 & 14 & 20 \\
\cline { 2 - 3 } Group 4 & 7 & 17 \\
\cline { 2 - 3 } & &
\end{tabular}

Fisher's exact test (one sided) $p=0.8883$

\begin{tabular}{l|c|c|}
\multicolumn{1}{c}{} & \multicolumn{1}{c}{ Accepted } & \multicolumn{1}{c}{ Rejected } \\
\cline { 2 - 3 } Group 5 & 15 & 27 \\
\cline { 2 - 3 } Group 6 & 19 & 35 \\
\cline { 2 - 3 } & &
\end{tabular}

Fisher's exact test (one sided) $p=0.5629$

Table 6 Number of monetary offers for a distribution of five/eight possible prizes that were accepted/rejected in groups 3-6.

Table 6 shows that there is no systematic difference in acceptance/rejection of "bank" monetary offers across groups 3 and 4 and across groups 5 and 6 . Thus, the decisions of Affari Tuoi contestants do not reveal any manifestable effect of nonlinear probability weighting.

\subsection{Yaari's Dual Model}

According to Yaari's model, an individual chooses lottery $L\left(x_{1}, 1 / n ; \ldots ; x_{n}, 1 / n\right)$, $x_{1}>x_{2}>\ldots>x_{n}$, over amount $y$ for certain if $\sum_{i=1}^{n}\left[w\left(\frac{i}{n}\right)-w\left(\frac{i-1}{n}\right)\right] \cdot x_{i} \geq y$, where $w:[0,1] \rightarrow[0,1]$ is a probability weighting function (e.g. Yaari, 1987). The probability weighting function is strictly increasing and $w(0)=0, w(1)=1$. Note that this model is a special case of rank-dependent expected utility theory where the utility function is linear.

To test Yaari's dual model, we consider the decisions of Affari Tuoi contestants who receive monetary offer $y$ for a $50 \%-50 \%$ chance to win either prize $x_{1}$ or prize $x_{2}$. According to Yaari's model, contestants reject "bank" offer if $x_{2}+w(1 / 2) \cdot\left(x_{1}-x_{2}\right) \geq y$, which is equivalent to $w(1 / 2) \geq\left(y-x_{2}\right) /\left(x_{1}-x_{2}\right)$. Thus, the higher is the ratio 
$z=\left(y-x_{2}\right) /\left(x_{1}-x_{2}\right)$, the more likely is a contestant to accept a "bank" offer (for a given probability weight $w(1 / 2))$.

For 41 Affari Tuoi contestants who received a monetary offer for a distribution of two prizes, a simple logit regression $\operatorname{Pr}("$ accept" $)=\exp \left(\beta_{0}+\beta_{1} \mathbf{z}\right) /\left(1+\exp \left(\beta_{0}+\beta_{1} \mathbf{z}\right)\right)$ yields an estimate of regression coefficients, with standard errors in parenthesis, of $\beta_{0}=0.2448(0.2243)$ and $\beta_{1}=0.5346(0.5782)$. Thus, there is no statistically significant relationship between the ratio $z=\left(y-x_{2}\right) /\left(x_{1}-x_{2}\right)$ and the likelihood that contestants accept "bank" offers. Apparently, Affari Tuoi contestants facing a decision problem with high ratio $z$, are also more likely to possess a higher probability weight $w(1 / 2)$. It is difficult to reconcile this finding within the framework of Yaari's dual model, because probability weights are assumed to be independent of the monetary outcomes.

\subsection{Prospective Reference Theory}

According to prospective reference theory, an individual maximizes a weighted average of the expected utility of a lottery and the expected utility from receiving every possible outcome of the lottery with equal probability (Viscusi, 1989). Formally, an individual chooses risky lottery $L\left(x_{1}, 1 / n ; \ldots ; x_{n}, 1 / n\right)$, over amount $y$ for certain if $\lambda \frac{1}{n} \sum_{i=1}^{n} u\left(x_{i}\right)+(1-\lambda) \frac{1}{n} \sum_{i=1}^{n} u\left(x_{i}\right)=\frac{1}{n} \sum_{i=1}^{n} u\left(x_{i}\right) \geq u(y)$, where $u: \mathrm{R} \rightarrow \mathrm{R}$ is a (Bernoulli) utility function over money and $\lambda \in[0,1]$ is the weight of the relative information content. Affari Tuoi television show employs only lotteries with equiprobable outcomes. Thus, in our dataset the prediction of prospective reference theory is identical to the prediction of expected utility theory (for any possible weight of the relative information content). 


\subsection{Disappointment Aversion Theory}

According to disappointment aversion theory, an individual experiences disappointment (elation) when a realized outcome of a lottery is below (above) its certainty equivalent. Ex ante, an individual anticipates future disappointment or elation and attempts to minimize ex post disappointment (Gul, 1991). Formally, an individual chooses a risky lottery $L\left(x_{1}, 1 / n ; \ldots ; x_{n}, 1 / n\right), x_{1}>x_{2}>\ldots>x_{n}$, over a sure amount $y$ if $\frac{1}{1+m \beta} \frac{1}{n} \sum_{i=1}^{n-m} u\left(x_{i}\right)+\frac{1+\beta}{1+m \beta} \frac{1}{n} \sum_{i=n-m+1}^{n} u\left(x_{i}\right) \geq u(y)$, where $m \in\{1, \ldots, n-1\}$ is a number of disappointing outcomes in lottery $L, \beta \geq 0$ is a subjective parameter that captures disappointment averse preferences and $u: \mathrm{R} \rightarrow \mathrm{R}$ is a (Bernoulli) utility function.

To test the prediction of disappointment aversion theory, we analyze the decisions of Affari Tuoi contestants who received a monetary offer for a distribution of eight, five and two prizes. Consider the five lowest prizes from Figure 1 ( $€ 0.01, € 0.20, € 0.50, € 1$ and $€ 5$ ). Given that the other prizes from Figure 1 are significantly higher monetary amounts, we assume, for simplicity, that these five lowest prizes yield the same utility. Without loss of generality, this utility can be normalized to zero. In our recorded sample, prizes $€ 0.01, € 0.20, € 0.50, € 1$ and $€ 5$ are always disappointing prizes. ${ }^{28}$ An individual then chooses a risky lottery $L$ over monetary amount $y$ for certain if $\frac{1}{1+(m+k) \beta} \frac{1}{n} \sum_{i=1}^{n-m} u\left(x_{i}\right)+\frac{1+\beta}{1+(m+k) \beta} \frac{1}{n} \sum_{i=n-m+1}^{n-k} u\left(x_{i}\right) \geq u(y)$, where $k \in\{1, \ldots, 5\}$ is the number of prizes of lottery $L$ that are below or equal to $€ 5$ and $m$ is the number of disappointing

\footnotetext{
${ }^{28}$ When contestants receive a monetary offer for a distribution of eight (five) equiprobable prizes, at least two (one) of these prizes are (is) at least 1000 times higher than $€ 5$. Thus, for any plausible level of risk aversion, the certainty equivalent of such lotteries is significantly above $€ 5$ i.e. outcomes $€ 0.01, € 0.20$, $€ 0.50, € 1$ and $€ 5$ are disappointing outcomes. When contestants receive a monetary offer for a distribution of two prizes, one of which is below or equal to $€ 5$, the low prize is obviously a disappointing prize. In our recorded sample there are also two instances when a contestant received a monetary offer for lotteries $(€ 1,0.5 ; € 0.50,0.5)$ and $(€ 1,0.5 ; € 0.20,0.5)$. We excluded these two cases from current analysis.
} 
prizes of lottery $L$ that are higher than $€ 5$. Thus, according to disappointment aversion theory, the higher is $k$, the more likely is a contestant to accept "bank" offer.

Contrary to the theoretical prediction, Table 7 shows that Affari Tuoi contestants tend to accept "bank" offers less frequently when they face lotteries with a high number of small disappointing prizes. However, this tendency is not statistically significant. Thus, Affari Tuoi contestants do not appear to be averse to small disappointing prizes. The presence of such prizes rather induces a risk-seeking behavior.

\begin{tabular}{|c|c|c|c|c|c|c|}
\hline \multirow{3}{*}{$\begin{array}{c}\text { Number of } \\
\text { small }(\leq € 5) \\
\text { disappointing } \\
\text { prizes }\end{array}$} & \multicolumn{6}{|c|}{ Number of contestants who face a lottery with... } \\
\hline & \multicolumn{2}{|c|}{8 prizes and... } & \multicolumn{2}{|c|}{5 prizes and... } & \multicolumn{2}{|c|}{2 prizes and... } \\
\hline & $\begin{array}{c}\text { Accept } \\
\text { offer }\end{array}$ & $\begin{array}{c}\text { Reject } \\
\text { offer }\end{array}$ & $\begin{array}{c}\text { Accept } \\
\text { offer }\end{array}$ & $\begin{array}{c}\text { Reject } \\
\text { offer }\end{array}$ & $\begin{array}{c}\text { Accept } \\
\text { offer }\end{array}$ & $\begin{array}{c}\text { Reject } \\
\text { offer }\end{array}$ \\
\hline $\mathbf{0}$ & 1 & 5 & 12 & 10 & 12 & 12 \\
\hline 1 & 4 & 27 & 12 & 28 & 6 & 9 \\
\hline 2 & 5 & 37 & 9 & 19 & & \\
\hline 3 & 1 & 27 & 1 & 4 & & \\
\hline 4 & 0 & 4 & 0 & 1 & & \\
\hline
\end{tabular}

Table 7 Decisions of contestants and the number of small disappointing prizes in a risky lottery

\section{Conclusion}

The television show Affari Tuoi provides an interesting natural experiment that allows to test the predictions of different decision theories. Contestants representing the adult population of Italy face a sequence of binary choices between a risky lottery with equiprobable prizes and a monetary amount for certain. The show provides very high real incentives with prizes ranging from one cent to half a million euros. This allows us to investigate decision making in a domain that is not feasible in conventional laboratory experiments. However, we observe only few choices made by each contestant, which mostly restricts our analysis to a between-subject design. Random events play a crucial role in this natural experiment, because they determine the distribution of possible prizes 
that a contestant is facing. This enables us to allocate contestants across randomized treatments.

We test the predictions of ten well-known decision theories that are usually contested against each other for the best explanation of behavioral patterns observed in laboratory experiments. The main findings of this natural experiment can be summarized as follows. On the one hand, Affari Tuoi contestants clearly violate the assumption of risk neutrality and the assumption of loss aversion of prospect theory. On the other hand, the behavior of Affari Tuoi contestants supports the assumption of regret aversion of regret theory and fanning-out hypothesis of weighted utility and skew-symmetric bilinear utility theories. Predictions of other theories are neither supported nor rejected (e.g. simple or rank-dependent non-linear probability weighting and disappointment aversion).

It is important to emphasize that none of contestants actually violated expected utility theory or any of the generalized non-expected utility theories that incorporate the former as a special case. However, contestants managed to avoid ex post regret, which is difficult to reconcile with any other decision theory but regret theory, and revealed significantly higher risk aversion when facing stochastically dominating lotteries, which is predicted by decision theories that incorporate the fanning-out hypothesis. Obviously, these results have important implications for future theoretical work.

In contrast to numerous laboratory experiments that document non-linear probability weighting, our natural experiment provides no support for this phenomenon. This somewhat surprising lack of evidence suggests that more empirical work has to be done outside the laboratory. Currently, we plan to extend our analysis to incorporate the Deal or No Deal shows broadcasted in Switzerland and the U.S., where contestants make similar decisions as in Affari Tuoi. 


\section{References}

Allais, M. (1953) "Le Comportement de l'Homme Rationnel devant le Risque: Critique des Postulates et Axiomes de l'École Américaine" Econometrica 21, 503-546

Antonovics, K., P. Arcidiancono, and R. Walsh (2005): "Games and Discrimination: Lessons From The Weakest Link," Journal of Human Resources, 40(4), 918-947.

Beetsma, R. M. and P.C. Schotman (2001): "Measuring Risk Attitudes in a Natural Experiment: Data from the Television Game Show Lingo," Economic Journal, 111(474), 821-848.

Bennett, R.W. and K. A. Hickman (1993): "Rationality and 'The Price Is Right'," Journal of Economic Behavior and Organization, 21(1), 99-105.

Berk, J. B., E. Hughson and K. Vandezande (1996): "The Price Is Right, But Are the Bids? An Investigation of Rational Decision Theory," American Economic Review, 86(4), 954-970.

Blavatskyy, P. and G. Pogrebna (2006) "Loss Aversion? Not with Half-a-Million on the Table!" available at IEW WP 274 http://www.iew.unizh.ch/wp/iewwp274.pdf

Bombardini, M. and F. Trebbi (2005): "Risk Aversion and Expected Utility Theory: A Field Experiment with Large and Small Stakes," Unpublished manuscript, available at http://www.people.fas.harvard.edu/ trebbi/BT_17nov2005.pdf

Chew, S. (1983) "A generalization of the quazilinear mean with applications to the measurement of income inequality and decision theory resolving the Allais paradox" Econometrica 51, 1065-1092

Chew, S. and McCrimmon, K. (1979) "Alpha-nu choice theory: an axiomatization of expected utility" University of British Columbia Faculty of Commerce working paper \#669

Chew, S., L. Epstein and U. Segal (1991) "Mixture symmetry and Quadratic utility" Econometrica 59, 139-164

De Roos, N. and Y. Sarafidis (2006) "Decision Making under Risk in Deal or no Deal" available at SSRN: http://ssrn.com/abstract $=881129$

Fishburn, P. (1983) “Transitive measurable utility” Journal of Economic Theory 31, 293317 
Fishburn, P. (1988) "Nonlinear preference and utility theory" Baltimore, John Hopkins University Press

Gul, F: (1991) “A Theory of Disappointment Aversion” Econometrica 59, 667-686

Harless, D. and C. Camerer (1994) The predictive utility of generalized expected utility theories, Econometrica 62, 1251-1289

Hey, J. (2001) “Does repetition improve consistency?” Experimental economics 4, 5-54

Hey, J.D. and C. Orme (1994) Investigating generalisations of expected utility theory using experimental data, Econometrica 62, 1291-1326

Kahneman, D. and Tversky, A. (1979) "Prospect theory: an analysis of decision under risk" Econometrica 47, 263-291

Machina, M. (1982) "'Expected utility' analysis without the independence axiom" Econometrica 50, 277-323

Markowitz, Harry M. (1952) “The Utility of Wealth,” Journal of Political Economy 60, $151-158$

Mulino, D, R. Scheelings, R. Brooks and R. Faff (2006) "Is a Dollar in the Hand Worth Two in a Lottery? Risk Aversion and Prospect Theory in Deal or No Deal", Monash University working paper

Friedman, M. and L. Savage (1948) "The Utility Analysis of Choices Involving Risk" Journal of Political Economy 56, 279-304

Gertner, R. (1993): "Game Shows and Economic Behavior: Risk Taking on 'Card Sharks'," Quarterly Journal of Economics, 108(2), 507-522.

Kahneman, D. and A. Tversky (1979) "Prospect Theory: an Analysis of Decision Under Risk" Econometrica 47, 263-291

Levitt, S. D. (2004) “Testing Theories of Discrimination: Evidence from Weakest Link," Journal of Law and Economics, 47(2), 431-52.

Loomes, G., Starmer, Ch. and Sugden, R. (1992) "Are preferences monotonic? Testing some predictions of regret theory" Economica 59, 17-33

Loomes, G. and Sugden, R. (1987) "Some applications of a more general form of regret theory" Journal of Economic Theory 41, 270-287

Metrick, A. (1995): “A Natural Experiment in 'Jeopardy!'," American Economic Review, 85(1), 240-253. 
Post, T., M. Van den Assem, G. Baltussen and R. Thaler, (2004) "Deal or No Deal? Decision Making Under Risk in a Large-Payoff Game Show" available at SSRN: http://ssrn.com/abstract $=636508$

Quiggin, J. (1982) “A Theory of Anticipated Utility" Journal of Economic Behavior and Organization 3, 323-43

Starmer, Ch. (1992) "Testing new theories of choice under uncertainty using the common consequence effect" Review of Economic Studies 59, 813-830

Starmer, Ch. (2000) "Developments in non-expected utility theory: the hunt for a descriptive theory of choice under risk" Journal of Economic Literature 38, 332382

Tversky, A. and D. Kahneman (1992) "Advances in Prospect Theory: Cumulative Representation of Uncertainty" Journal of Risk and Uncertainty 5, 297-323

Viscusi, W. K. (1989) "Prospective Reference Theory: Toward an Explanation of the Paradoxes" Journal of Risk and Uncertainty 2, 235-264 